\title{
New associate editor: Reha N. Tandogan
}

\author{
Jon Karlsson ${ }^{1} \cdot$ Roland Becker $^{2} \cdot$ Michael Hirschmann $^{3,4} \cdot$ Volker Musahl $^{5}$
}

Published online: 25 August 2018

(c) European Society of Sports Traumatology, Knee Surgery, Arthroscopy (ESSKA) 2018

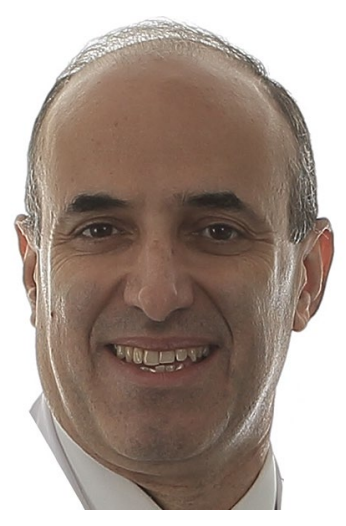

Dr. Reha N. Tandogan is new Associate Editor of KSSTA, effective July 1, 2018. He will mainly be responsible for manuscripts related to Total and Uni-knee Arthroplasties, Osteotomies and Osteoarthritis in general.

Dr. Tandogan graduated from Hacettepe University Medical School in 1985 with honours. He underwent specialty training at the Hacettepe University Medical School, Department of Orthopaedics and Traumatology, in Ankara, Turkey.

Jon Karlsson

jon.karlsson@telia.com

Roland Becker

roland_becker@yahoo.de

1 Department of Orthopaedics, Sahlgrenska University Hospital, Sahlgrenska Academy, Gothenburg University, Göteborg, Sweden

2 Department of Orthopaedics and Traumatology, Hospital Brandenburg, Medical School Theodor, Fontane, Hochstrasse 26, 14770 Havel, Bradenburg, Germany

3 Department of Orthopaedic Surgery and Traumatology, Kantonsspital Baselland (Bruderholz, Liestal, Laufen), Bruderholz, Switzerland

4 University of Basel, Basel, Switzerland

5 Orthopaedic Surgery and Bioengineering, UPMC Center for Sports Medicine, University of Pittsburgh, Pittsburgh, PA, USA
He worked as an assistant to the late Dr. Gerard Bascoulergue in the Arthroscopy and Sports Traumatology Clinic of Institut Calot (Berck, France) for a year. He then trained with the late Prof. Robert W. Jackson, Baylor University, Dallas, Texas. He became an associate professor in 1995 and moved to Department of Orthopaedics and Traumatology, Baskent University. He was appointed chairman of the department in 1998 and also undertook the duties of the chairman of the Sport Sciences department in 2001. He was appointed full professor in 2001. Baskent University was recognized as an ISAKOS Approved Teaching Center and has hosted several international fellows during his chairmanship. He went on to private practice and is currently a senior member of Cankaya Orthopaedics, a 14-surgeon group specializing in arthroscopic surgery and arthroplasty.

Dr. Tandogan was awarded the International Arthroscopy Association Linvatec Award in 1995 and has been a member of ISAKOS since its inception. He has been an ESSKA member since 1996. He served three terms on the executive board of the Turkish Society of Sports Traumatology, Arthroscopy and Knee Surgery, and is currently the Chair of the Arthroplasty Committee. He has organized numerous arthroscopy and arthroplasty courses; he also designed and developed several models for hands-on arthroscopic training. He was the President of the 11th Turkish Sports Traumatology Arthroscopy and Knee Surgery Congress with international participation that took place in Ankara in 2012. He also served as president of the Turkish Society of Sports Traumatology for two terms, organizing several cadaver courses, symposia and editing two books.

In 2015, Dr. Tandogan was elected as a board member of European Knee Associates (EKA); a section of ESSKA, focusing on the treatment and education of degenerative knee disorders, knee arthroplasty and joint preservation surgery. He is currently heading the tibial component rotation focus group.

He is the author of one English and eight Turkish books on Knee Surgery and Sports Traumatology. He has lectured extensively and published 133 scientific articles (67 in international journals) and has an $\mathrm{H}$-index of 23. His 
main focus is arthroscopic and reconstructive surgery of the knee, including multi-ligament injuries, cartilage repair, osteotomies, primary and revision knee arthroplasty. He has been a reviewer for the ESSKA journal since 2014 and was selected reviewer of the year in 2016. He has served twice as a guest editor for the June 2015 and August 2016 issues of the KSSTA journal and is currently an editorial board member. He has also served for 4 years as the founding editor of Journal of the Turkish Orthopaedic and Traumatology Association.

We welcome Reha N. Tandogan as new Associate Editor of our journal. 